\title{
Climate change and seasonal reproduction in mammals
}

\author{
F. H. Bronson* \\ Section of Integrative Biology, The University of Texas at Austin, Austin, TX, USA
}

\begin{abstract}
Seasonal reproduction is common among mammals at all latitudes, even in the deep tropics. This paper (i) discusses the neuroendocrine pathways via which foraging conditions and predictive cues such as photoperiod enforce seasonality, (ii) considers the kinds of seasonal challenges mammals actually face in natural habitats, and (iii) uses the information thus generated to suggest how seasonal reproduction might be influenced by global climate change. Food availability and ambient temperature determine energy balance, and variation in energy balance is the ultimate cause of seasonal breeding in all mammals and the proximate cause in many. Photoperiodic cueing is common among long-lived mammals from the highest latitudes down to the mid-tropics. It is much less common in shorter lived mammals at all latitudes. An unknown predictive cue triggers reproduction in some desert and dry grassland species when it rains. The available information suggests that as our climate changes the small rodents of the world may adapt rather easily but the longer lived mammals whose reproduction is regulated by photoperiod may not do so well. A major gap in our knowledge concerns the tropics; that is where most species live and where we have the least understanding of how reproduction is regulated by environmental factors.
\end{abstract}

Keywords: seasonality; gonadotropin-releasing hormone; foraging conditions; energy balance; photoperiod; the tropics

The world's climate has changed radically from hot to cold and wet to dry and back again throughout its 4.5 billion-year history. When mammals first appeared 250 million years ago, the world was warming and drying out and there was only one landmass in existence, the supercontinent of Pangea. Some parts of Pangea experienced extreme seasonal cycles of climate and food availability, while others did not (Crowley 1994). Thus, some of the first mammals probably reproduced only seasonally, while others reproduced throughout the year. As Pangea broke up and the new continents spread around the world, the Earth's climate continued to shift from one extreme to the other and the expanding numbers of mammals continued to adapt reproductively. The Cretaceous mass extinction of $65 \mathrm{Ma}$ opened the door to massive adaptive radiation and today more than 4000 species of mammals can be found surviving and reproducing in a huge diversity of habitats, most characterized by some degree of seasonal variation. The world's climate is changing rapidly now and there is a concern that many species may face extinction if they cannot evolve new seasonal strategies (Bradshaw \& Holzapfel 2006).

The objectives of this paper are threefold: first, to consider what laboratory experimentation has taught us about the neuroendocrine pathways that link seasonal factors to the reproduction of mammals; second, to relate the knowledge gained in the laboratory to the kinds of challenges mammals actually face in natural

*bronson@mail.utexas.edu

One contribution of 11 to a Theme Issue 'Impacts of environmental change on reproduction and development in wildlife'. habitats; third, to use the information generated by the first two objectives to consider how mammals might or might not adapt seasonally to global climate change.

Two kinds of seasonal factors are of concern. The first is foraging conditions as they influence energy balance. This is the ultimate cause of seasonal reproduction in all mammals and the proximate cause in many. The second includes predictive cues like photoperiod. The neuroendocrine pathways of concern are those that couple energy balance and cues like photoperiod to neurons in the brain that secrete gonadotropin-releasing hormone $(\mathrm{GnRH})$. The GnRH neurons are distributed widely in the forebrain but most are found in the anterior hypothalamus and pre-optic area. They terminate in the median eminence where GnRH enters the pituitary portal system and regulates the secretion of the gonadotropins. The gonadotropins control the secretion of the gonadal steroids and, in turn, the steroids feed back to control the secretion of the gonadotropins. Negative feedback occurs routinely in both sexes and positive feedback results in ovulation in females.

Despite being widespread in the forebrain, the GnRH neurons are able to act in a synchronized manner, generating distinct pulses in the release of this neuropeptide. Thus arises the useful concept of a GnRH pulse generator even though it is not yet completely defined neurologically. The activity of the $\mathrm{GnRH}$ pulse generator is often measured by the frequency of pulses of luteinizing hormone $(\mathrm{LH})$ in the blood; few or no pulses are seen in reproductively inactive animals while many are seen in reproductively active animals. 


\section{ENERGY BALANCE}

When the energetic costs of foraging exceed the calories gained, the result is negative energy balance and this depresses the activity of the GnRH pulse generator. This mode of regulating reproduction is characteristic of all mammals and if severe enough it overrides any factor promoting reproduction. As shown conceptually in figure 1 , the calories obtained from a mammal's food can either be used to do work of various kinds or stored as glycogen in the liver or as lipids in body fat. Some of the body's many energetic needs must be satisfied or the mammal dies. Included in this category are the basic cellular, tissue and organ activities necessary for homeostasis, as well as the energetic costs of thermoregulation and foraging. Functions such as growth and reproduction can be delayed when foraging conditions are too costly energetically, and both can be abandoned in the face of severe negative energy balance.

As the first of two examples of how negative energy balance influences reproduction, ovulation is exceptionally sensitive to both low temperature and food restriction in small mammals (much more so than spermatogenesis). The ratio of surface area to body mass makes retaining heat difficult for them and, additionally, they have relatively little energy stored as fat to counter energetic challenge. As shown in experiments with laboratory mice, restricting their food intake blocks ovulation. So does exposure to cold if the mice are not allowed to increase their food intake to compensate for the increased thermoregulatory costs. If allowed to increase their food intake, however, female mice can ovulate and reproduce at surprisingly low temperatures (Manning \& Bronson 1990).

The second example involves humans. Puberty is delayed dramatically among teenage girls training strenuously for ballet and ovulation is blocked among adults running long distances because the individuals involved do not consume enough food to maintain more than minimal positive energy balance (reviewed by Bronson 1995). The same effect can be seen among primitive pastoralists in Africa who work hard and eat little during the harsh dry season and in primitive hunter-gatherers in Africa and elsewhere who spend lots of energy searching but finding little food during the annual drought (Ellison 2001).

Experimental interest in the neuroendocrine pathway(s) via which negative energy balance suppresses the GnRH pulse generator has spawned a huge number of papers and almost as many hypotheses. One of the simplest hypotheses that nevertheless accommodates much of what has been learned is the 'metabolic fuel hypothesis' (Schneider 2004; Wade \& Jones 2004). This hypotheses suggests that cells in the area postrema of the hindbrain monitor circulating levels of oxidizable metabolic fuels such as glucose and fatty acids. When there is insufficient metabolic fuel in circulation to support all of the functions seen in figure 1, this information is transmitted to the forebrain via catecholamine and neuropeptide $\mathrm{Y}$ projections where they depress the GnRH pulse generator either relatively directly or indirectly via corticotropin-releasing hormone. Considerable data support this hypothesis including a solid

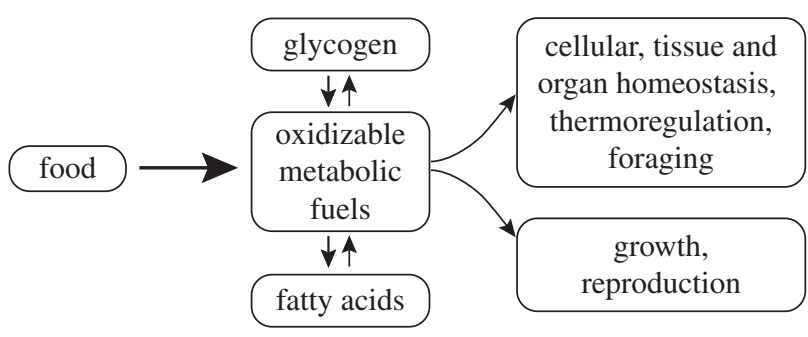

Figure 1. Energy balance as it relates to the priorities of various physiological functions in mammals.

demonstration that low circulating levels of glucose indeed do suppress the activity of the GnRH neurons (Zhang et al. 2007).

While there is a relatively direct connection between circulating levels of metabolic fuels and the $\mathrm{GnRH}$ pulse generator, this might not be the only energyrelated pathway influencing the secretion of this neuropeptide. The overall control of energy balance is an immensely complex process and a number of pathways involved in it might secondarily influence the activity of GnRH neurons. Peripheral signals influencing energy balance and thus possibly GnRH secretion could come from the liver, pancreas, stomach, duodenum or adipose tissue, and these signals could be sent to the brain via the vagus nerves or by hormones such as leptin, insulin, insulin-like growth factor 1 or ghrelin. These hormones could act directly on the neural circuits controlling the GnRH neurons or they could act by modulating the availability of metabolic fuel. Likewise, the neuropeptides regulating $\mathrm{GnRH}$ secretion in the forebrain could also include galanin, orexin, the urocortins and endogenous opioids. Recent interest has focused on kisspeptin, the product of the KISS1 gene. The presence of kisspeptin is necessary for normal reproductive development and it can override the reproductively detrimental effect of mild food restriction (Castellano et al. 2005). Precisely how this neuropeptide relates to the overall control of GnRH secretion by energy balance and thus seasonality is an intriguing question awaiting an answer (Revel et al. 2007).

\section{SEASONAL PREDICTORS}

Many mammals living at the higher latitudes rely on variation in day length to prepare in advance for seasonal change in foraging conditions rather than reacting only after the change of seasons is upon them (Goldman et al. 2004; Bradshaw \& Holzapfel 2007). The ability to do this requires endogenous timing mechanisms as well as circuits linking the retina to the GnRH secreting neurons. Some species with short life expectancies use an interval timer that measures time in months (in this paper, short life expectancy is defined as less than six months; longer life expectancy is defined as more than 1 year). Paul et al. (2008) has likened this kind of timer to an hourglass that measures a set period of weeks or months from a starting point in time. When maintained outside in the temperate zone, Syrian hamsters (Mesocricetus auratus) start breeding in the spring and cease breeding in the autumn. In the laboratory, 
their testes regress sharply when day length falls below a critical threshold of $12.5 \mathrm{~h}$. In the wild, this brings an end to the breeding season in the late summer. Reproductive activity returns after an endogenously generated period of photorefractoriness the duration of which is determined by the hourglass timer noted above (Herbert 1989). In the wild, this restarts the breeding season in the spring (Pendergast 2005).

At least some longer lived species with longer periods of gestation rely on an endogenous clock mechanism that oscillates continuously with a period that is less than a year and thus must be reset periodically to keep pace with the Earth's 365-day cycle of seasons (Zucker 2001). Domestic sheep housed outside in the temperate zone begin breeding in the early autumn and cease in the winter. This ensures that lambs will be born in the spring or early summer when grasses are maximally available and maximally nutritious. In the ewe, this involves a clock-driven, endogenously generated, annual cycle of sensitivity of the GnRH pulse generator to negative feedback by oestradiol. Exposure to the long days of summer increases the sensitivity of the GnRH neurons to oestradiol, thereby depressing $\mathrm{GnRH}$ pulsing and inducing seasonal anestrous. Exposure to the shortening days of autumn decreases the sensitivity of the GnRH neurons to oestradiol, thereby inducing estrous cycles (Woodfill et al. 1994; Malpaux et al. 2002). The mechanisms controlling the sensitivity of the GnRH neurons to oestradiol are unclear at this time.

Studies using a variety of mammals have revealed several components of the pathway via which day length regulates the $\mathrm{GnRH}$ pulse generator independent of the timing mechanisms noted above. (e.g. Malpaux et al. 2002). Information about day length passes from the retina via the retinohypothalamic tract to the suprachiasmatic nucleus (SCN) of the hypothalamus where it is integrated with a circadian oscillator. The SCN provides input to the paraventricular nucleus and from there neuronal projections pass caudally to the superior cervical ganglia in the spinal cord. From there sympathetic adrenergic neurons pass back rostrally to the pineal gland where melatonin is secreted at a much higher rate during the dark period of the day than during the light period. The duration of the night-time rise in circulating levels of melatonin provides a way for the brain to measure and react to variation in day length.

It is thought that the melatonin signal is decoded at the molecular level in melatonin receptor expressing cells rather than directly on the GnRH neurons but the circuitry coupling these two entities is unclear at this time, as are the molecular mechanisms involved in the hourglass and circannual clock mechanisms. As reviewed by Pendergast (2005), some candidate genes have been identified but research in this area lags far behind the rapid advancements being made in understanding the molecular basis for circadian time keeping (e.g. Takahashi et al. 2008).

It is probable that all mammals have at least some elements of a pathway that starts with the retina and ends at the GnRH pulse generator. In some species, the pathway is complete and functional; in others, it is not. The robust movement of the continental plates over the past $250 \mathrm{Myr}$ must have ensured that somewhere in the ancestry of each of today's species are ancestors that experienced seasonal variation powerful enough for natural selection to have favoured photoperiod cueing. For example, what would become equatorial Africa was in the southern temperate zone when the mammals first appeared on Pangea.

The human is probably an example of a species that retains only bits and pieces of this pathway. There are many papers documenting seasonal changes in gonadotropin or melatonin titres in one human population or another (e.g. Kauppila et al. 1987). There are also papers documenting seasonal cycles in births and it has been suggested that all of this reflects regulation of conception by photoperiod (Roenneberg \& Aschoff 1990). On evolutionary grounds, it has been suggested that photoperiodic regulation of reproduction indeed might be found in some individuals in the world, but not in most (Bronson 2004). Nevertheless, overall, there really is not any good evidence that the annual cycle of births in humans reflects control by photoperiod as opposed to food availability, potent cultural variables or the effect of summer heat.

\section{SEASONAL REPRODUCTION IN NATURAL POPULATIONS}

All latitudes find some mammals reproducing seasonally, even in the deep tropics. The energetic costs of reproduction are huge, and when the cost to gain ratio of foraging varies seasonally, births must occur when the muscle and thermoregulatory costs of obtaining food are most favourable. The energetic costs for males are mostly behavioural and in most but not all cases they are relatively minor compared with the caloric demands of lactation. As an example of the challenge small females face in the later stages of lactation, a female shrew (Blarina brevicada) weighing $11 \mathrm{~g}$ must find enough food to sustain itself and produce enough milk to sustain $55 \mathrm{~g}$ of offspring (Pearson 1944). Obviously, shrews can reproduce only during the most energetically favourable part of the year as determined by ambient temperature as well as food availability.

Ecologists are beginning to assess reproductive costs in wild populations. Laundre \& Hernandez (2003), for example, monitored the daily activity of coyotes wearing radio collars in the Great Basin desert of the western USA where they feed mostly on lagomorphs and small rodents. Locomotion and thus energy expenditures were calculated in calories and then transformed into the number of prey items required to balance the expenditures. Thus, male coyotes need to consume either 192 lagomorphs or 3681 rodents per year to maintain their normal level of activity, reproductive and non-reproductive. Excluding reproduction, females need less, either 162 lagomorphs or 3110 rodents per year. To support the one reproductive cycle the coyotes have each year, from oestrous to weaning, the female needs to consume an additional 37 lagomorphs or 700 rodents (an increase of $18 \%$ over the annual total). The female does not have to kill all these animals; the male parent helps out a little when the female is first 
suckling and cannot leave the burrow for an extended period of time.

\section{(a) The ArcticlAntarctic}

Foraging costs vary dramatically with latitude. Scarce food and low temperatures combine to make the energetic costs of foraging too high for most mammals to reproduce during the long Arctic winter. Whether denizens of tundra or taiga (northern boreal forest), the long-lived mammals of the Arctic such as the caribou-called the reindeer in Europe/Asia (Rangifer tarandus) - and the Arctic fox (Vulpes lagopus) give birth in the spring or early summer. An interesting variation is the polar bear that hibernates during the summer and gives birth in its hibernaculum in order to be free to hunt seals when the ice pack is solid in the winter. It is assumed that the seasonal reproduction of this long-lived species is regulated by photoperiod but how it does so in the face of constant darkness during the winter and constant light during the summer is an interesting question. Experiments with reindeer suggest that the secretion of melatonin in these mammals is uncoupled from its circadian control and, instead, is driven directly by the light cycle for a few weeks in the spring and again in the autumn (Stokkan et al. 2007). The result can be a highly synchronized birthing period (Skogland 1989).

As might be expected, the small mammals of the Arctic usually reproduce during the warmer parts of the year but winter reproduction has been documented occasionally in several species of voles and lemmings, including the following genera: Microtus, Clethrionomys, Lemmus and Dicrostonyx (Kaikusalo \& Tast 1984; Millar 2001). A degree of control by photoperiod has been seen in some species (e.g. Gower et al. 1997) but experimental evidence strongly suggests that food availability and the temperature-insulating effect of deep snow are the major factors allowing them to do this. While the ability of such small animals to reproduce in such energetically challenging conditions has been called a 'physiological miracle' (Krebs 1993), it may be even more widespread than thought and, as will be noted shortly, it may involve individual variation in reproductive photoresponsiveness.

\section{(b) The temperate zone}

Most of the longer lived mammals of the temperate zone reproduce seasonally, timing their mating such that the young are born when foraging conditions are optimal. It is routinely assumed that the annual reproductive cycle of these animals is regulated by photoperiod as it is in the sheep and there is evidence to support this possibility. For example, controlled experiments have documented photoperiodic regulation in several species of seasonally breeding North American, European and Asian deer (e.g. Verme \& Ozoga 1987; Rolf \& Fisher 1996; Lincoln 1998). In order for births to occur in the spring when food is maximally available, conception in these animals must occur in the previous autumn. This, in turn, requires that testis growth be triggered by photoperiod in the preceding summer in order for the males to be ready to compete for females in the autumn rut.
Thus, bucks respond positively to the long days of summer with antler growth, a thickening neck and increasing aggressiveness.

Some and probably many species of short-lived mammals at the higher latitudes of the Temperate Zone show profound individual variation in response to photoperiod (reviewed by Bronson \& Heideman 1994; Pendergast et al. 2001). An individual living in the wild whose reproduction is totally dependent upon photoperiod may be living side by side with an individual of the same species that is totally insensitive to photoperiod or, indeed, somewhere in between these two extremes; the variation is continuous from totally responsive to totally unresponsive (figure 2). This strategy allows some members of a population to go into a photoperiod-determined survival mode during the winter with no chance to reproduce while other members of the population can reproduce opportunistically during the winter if they can survive and if they can find a good food source (Kerbeshian et al. 1994). This variation is heritable (Desjardins et al. 1986).

Individual variation in photoresponsiveness is probably much more common in small rodents than previously thought. Indeed, it is probably very common in these animals at all latitudes above $40^{\circ}$ (see Heideman et al. 1999). It has been documented in at least six species and four genera of European and North American rodents (e.g. Bronson \& Heideman 1994; Gockel \& Ruf 2001) including one species (Microtus agrestis) that occasionally reproduces during the winter above the Arctic circle (Kaikusalo \& Tast 1984). Thus, individual variation in degree of photoperiodic control could be involved in the winter breeding seen in the other microtine rodents residing in the Arctic. Individual variation is probably the basis for published conclusions suggesting that a rodent species is 'weakly' or 'incompletely' photoperiodic also (e.g. El-Bakry et al. 1998). Little is known about the neuroendocrine basis for this kind of variation except that non-responsive white-footed mice have twice as many $\mathrm{GnRH}$ neurons as responsive individuals (Avigdor et al. 2004).

At the lower latitudes of the Temperate Zone, the small mammals that have been tested are uniformly unresponsive to variation in photoperiod (e.g. Peromyscus leucopus in the southeastern USA; Lynch et al. 1981). As might be expected (Herbert 1989), the block between the retina and the GnRH pulse generator in these mice is downstream from the pineal (Lynch et al. 1982).

While latitude is important in determining seasonal regulation by photoperiod in the small rodents of the Temperate Zone, so is the ecosystem in which they reside (Bronson 1998). Regardless of latitude, responsiveness to photoperiod almost disappears in some of the desert and dry grassland species of the Temperate Zone because of the unpredictable pattern of rainfall and thus food availability (e.g. El-Bakry et al. 1999; Jackson \& Bernard 1999; Wube et al. 2008). Drought-breaking rain and the appearance of fresh green vegetation result in reproduction. In some cases, this probably reflects only a surge in available calories while in others a predictive cue of some 


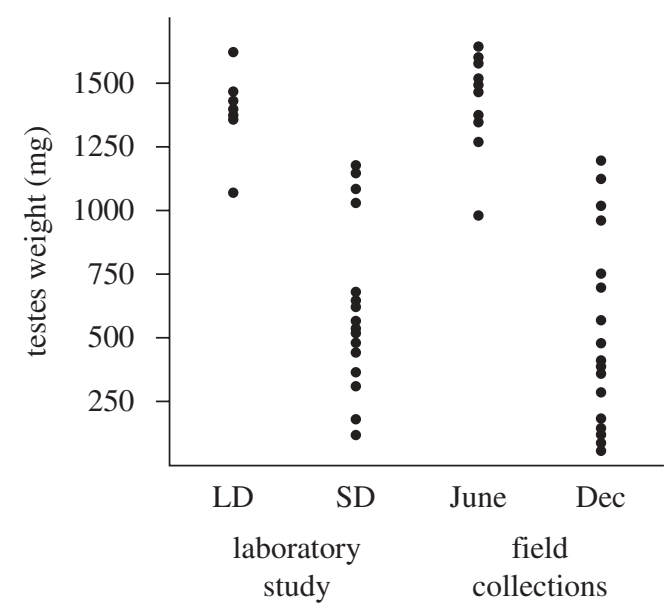

Figure 2. Testes weights of individual meadow voles (Microtus pennsylvanicus) held on long versus short day lengths in the laboratory compared with animals caught in the field in Pennsylvania at the summer versus winter solstice (adapted from Kerbeshian et al. 1994).

kind seems to be involved (Reichman \& van de Graaff 1975). A clue to this cue's identity may have come from studies of a non-desert rodent, the montane vole (Microtus montanus). A secondary plant compound may be acting as a predictor. Feeding voles fresh green shoots stimulates their breeding under the snow in mid winter when they normally do not breed and the plant compound that does this has been identified as 6-methoxbenzoxazolinone (Negus \& Berger 1977). Attempts to influence the reproduction of desert and dry grassland rodents by feeding them this and another secondary plant compound failed (White \& Bernard 1999) but a secondary plant compound of some kind still seems a likely cue. However, Shanas \& Haim (2004) have postulated that the cue is a sharp decrease in the salt content of vegetation after it rains in deserts.

\section{(c) The tropics}

Many habitats in the tropics are just as strongly seasonal as those in the temperate zone. Savanna and dry tropical forests are highly seasonal because of profound and relatively predictable variation in rainfall and thus food availability; in some regions, there is one rainy season a year, and in others, there are two. As might be expected then, a variety of seasonal patterns of reproduction can be seen at these latitudes. Individuals of some species show regular reproductive cycles that are out of phase with each other, the result being asynchronous reproduction at the population level (e.g. the white-tailed deer found in Venezuela; Goss 1983). In Costa Rica, cloud forest mice (Peromyscus nudipes) ovulate throughout the year but they cannot maintain pregnancy during the dry season because of insufficient food (Heideman \& Bronson 1993). The result is dramatic seasonal variation in the production of young. The well-studied chimpanzees (Pan troglodytes) found in gallery and dry forests show little synchrony at the population level and only a slight seasonal trend related to the rainy season (Wallis 1995). On the savanna in Kenya, one can find mild seasonality related to the rainy season or irregular and asynchronous reproduction dictated by long term - 2 or more years - patterns of rainfall (e.g. the warthog and zebra versus the giraffe; Ogutu et al. 2008).

There is no variation in day length at the equator but presumably photoperiod could be relied upon to harmonize reproduction with seasonal variation in rainfall and thus food availability at the higher latitudes of the tropics. On the basis of little evidence, a theoretical model for the relationship between latitude, lifespan and reproductive photoresponsiveness was suggested 20 years ago (Bronson 1989). Starting with longer lived mammals, the model in figure 3 predicts that photoresponsiveness in longer lived mammals is routinely enforced by photoperiod down to about $30^{\circ}$ latitude, below which it gradually becomes less useful until it is lost in the mid to deep tropics. The available data, while still quite limited, support this dimension of the model. Some mammals can detect and use annual variation in day length in the mid-tropics while others cannot. For example, a temperate breed of domestic sheep, the Suffolk, can detect and react reproductively to seasonal variation in photoperiod typical of $19^{\circ} \mathrm{N}$ (Arroyo et al. 2007) while, as expected, the same breed shows no response when exposed continuously to an equatorial $12 \mathrm{~h}$ of light per day (Jansen \& Jackson 1993). In contrast, one of the flying foxes (Pteropus rodricensis) breeds asynchronously when exposed in the laboratory to variation in photoperiod typical of their home at $23^{\circ}$ latitude (West 1985). The long-nosed bat (Anoura geoffroyi), a native of Trinidad at $10^{\circ}$ latitude, reproduces during one restricted and predictable breeding season each year. As shown in controlled, constant conditions, this reflects an endogenous, clock-driven rhythm of 7.5 months. The clock cannot be reprogrammed to this species' normal breeding cycle of 12 months by exposure to a wide variety of both stable and gradually changing photoperiods typical of tropical as well as temperate latitudes (Heideman \& Bronson 1994). Like the white-footed mice from the southeastern USA, the block in these bats is downstream from the secretion of melatonin.

An almost completely unexplored question relates to the kind of predictive cue that longer lived, seasonally breeding mammals use close to the equator where there is not enough variation in day length to predict oncoming rains and improved food availability. As far as the author knows, this question has been explored systematically only in the long-nosed bat noted above. The following treatments all failed to lengthen the endogenous 7.5-month circannual cycle of this species to the 12-month cycle seen in the wild: sun position and light intensity as mimicked by a small spotlight shifting position on a movable track, exposure to planes of polarized light that would be seen at dawn and dusk in the wild, wet and dry seasons in the room in which the bats were housed and varying the amount of protein in the bats' diet (Heideman 2000).

Referring back to the model shown in figure 3, while this model is relatively accurate for longer-lived mammals, the same cannot be said about short-lived 


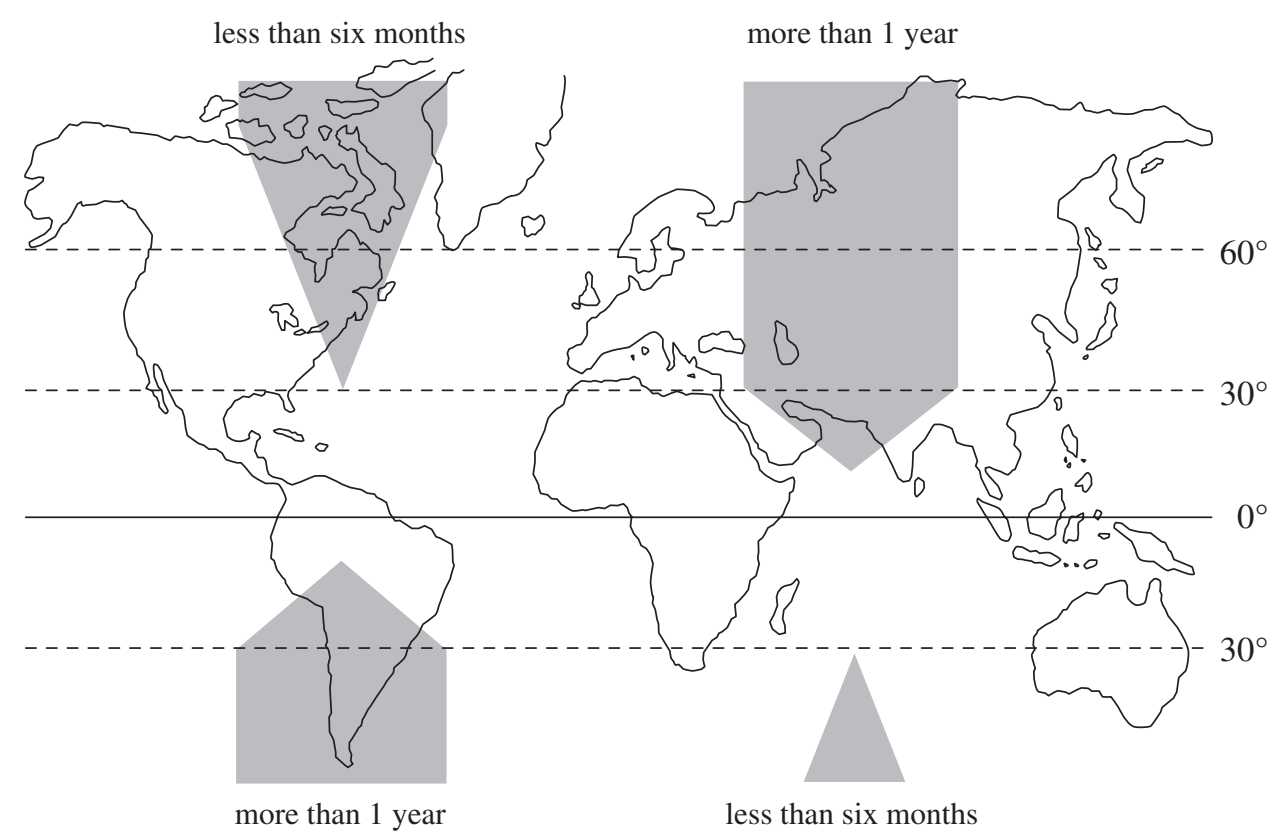

Figure 3. A theoretical scheme relating the use or disuse of photoperiodic cueing to latitude and lifespan. The shaded areas indicate the proportion of populations using photoperiod to time their seasonal reproduction for species whose life expectancy is less than six months versus more than 1 year (adapted from Bronson 1989).

mammals. As noted earlier, individual variation in photoresponsiveness is common at the higher latitudes of the Temperate Zone and might be responsible for the winter breeding seen in some rodents in the Arctic. Thus the uniformity of reliance on photoperiod in the Arctic as the model suggests is very likely wrong.

Based mostly on the logical expectation that opportunism would be the best strategy for short-lived animals in the warm climate of the tropics, the previously published model predicted that reproductive photoresponsiveness would be lost in short-lived species below $30^{\circ}$ latitude. Reproductive photoresponsiveness has been tested now in 10 additional species of tropical rodents. Three Central or South American rodents were shown to be uniformly unresponsive to photoperiod: Peromyscus aztecus, P. nudipes and Zygodontomys brevicauda (Bronson \& Heideman 1992; Heideman \& Bronson 1992; Demas \& Nelson 1998). Like the white-footed mice and the bat from Trinidad, the block in the cane mouse $(Z$. brevicauda) is located somewhere downstream from the pineal (Bronson \& Heideman 1992).

In marked contrast to what is seen in the Americas, and contrary to the model suggested in figure 3, five species of rodents from the Sahel region of Africa responded positively to the $2 \mathrm{~h}$ annual variation in day length characteristic of $14^{\circ}$ latitude when tested in the laboratory (Sicard et al. 1988). Unfortunately, this conclusion is based on single samples of circulating levels of testosterone. This hormone is secreted episodically, and assessing its blood level at one moment in time provides a poor indication of any potential seasonal effects (as opposed to variation in testes size, oestrous cycling or pregnancy). The seasonal patterns of reproduction are not well documented for these species but the Sahel is desert/dry grassland characterized by highly unpredictable rainfall. One certainly would expect opportunistic reproduction in this region so the question is why has natural selection not removed reproductive photoresponsiveness from these five species if, indeed, they are truly photoresponsive? Why is it still there when it must be a disadvantage? There is no ready answer to that question but this situation is not unknown in the Temperate Zone. As determined by testes size and breeding success, the California vole (Microtus californicus) acts like a long day breeder when tested in the laboratory but actually breeds during the winter when its food is maximally available in the wild (Nelson et al. 1983). Responsiveness to variation in photoperiod has also been seen in several species of opportunistically-breeding desert rodents in Egypt (Dipodillus dasyrurus, Acomys cahirinus, Gerbilus andersoni and Gerbilus pyramidum; El-Bakry et al. 1998) and Israel (Acomys russatus: Wube et al. 2008). Thus, there is no doubt that at least one species of rodent can override photoperiodic control, switching instead to opportunistic reproduction based on foraging conditions without selection acting against responsiveness to day length.

\section{KNOWN EFFECTS OF CLIMATE CHANGE ON SEASONAL REPRODUCTION IN MAMMALS}

The concerns about reproduction and climate change are more ecological than neurological, but it is worth noting that the last two decades have seen good progress in understanding how variation in photoperiod and energy balance modulate the activity of the GnRH pulse generator and research has at least started on understanding the molecular underpinnings of these pathways. Importantly, much of what has been learned in the laboratory is readily translatable 
into ecological and evolutionary concepts related to reproduction in natural populations.

That having been said, the key question is how will mammals react behaviourally, ecologically and genetically to a changing climate? There are many documented cases now of disturbed seasonal patterns owing to climate change in plants, insects, amphibians and birds (Parmesan 2007) and a temporal mismatch between the seasonal peak in births and the peak of foraging conditions has been seen twice in mammals. A $4^{\circ}$ increase in ambient temperature in western Greenland over a 7-year period has resulted in a potent temporal mismatch between the migration of caribou to their calving grounds and the appearance of the newly emerging vegetation they eat. The caribou are arriving long before snow melt makes their food available and the result has been a fourfold decrease in the production of weaned young (Post \& Forchhammer 2008).

The yellow-bellied marmots (Marmota flaviventris) of the Rocky Mountains are emerging from hibernation 38 days earlier now than they did 28 years ago but the snow when they emerge now is far too deep to forage for herbs successfully (Inouye et al. 2000). Marmots have one short breeding season a year. It occurs as soon as the females emerge from hibernation and almost 80 per cent of the variation in rate of pregnancy and litter size is explained by the time of snow melt and thus food availability (Van Vuren \& Armitage 1991).

\section{POTENTIAL EFFECTS OF CLIMATE CHANGE ON SEASONAL REPRODUCTION IN MAMMALS}

The overall objective of this paper was to develop a foundation of knowledge that could be used to suggest how seasonal reproduction might be influenced by a changing climate. It is more than a bit risky to make predictions based on little knowledge, but the present effort at least provides a target for future research. Two generalizations are possible. First, as suggested by the studies of caribou and marmots, the mammals that will probably be hardest hit by climate change will be the longer-lived species at the mid to higher latitudes whose reproduction is rigidly controlled by photoperiod. The annual cycle of hibernation and reproduction is controlled by photoperiod in marmots and this factor is likely important for the timing of caribou migrations as well.

Continuing this line of thought, the future will probably see shifts in species' ranges to higher latitudes as the climate warms. Thus, a key question is how rapidly can selection produce a new critical day length in long-lived mammals? Or, alternatively, how rapidly can selection eliminate photoperiodic control entirely and produce opportunists? The material used by selection is genetic variation within a population and we know almost nothing about that in longer lived mammals. To the author's knowledge, individual variation in photoresponsiveness has been documented in only one long-lived animal: the shorthaired Pelibuey sheep that is a native of Mexico, the Caribbean and northern South America. These animals show considerable individual variation in the onset of oestrus when housed outside at $19^{\circ} \mathrm{N}$ (Arroyo et al. 2007). The photoresponsive, longer lived mammals of the mid and higher latitudes will probably be hard hit by climate change but there is no way of predicting whether they will be able to successfully adapt to the new conditions or become extinct. That will be determined by whether selection can stay ahead of steadily increasing temperatures and changes in rainfall patterns.

The second generalization is easier to make. The small rodents - the mice and rats of the world-are probably going to adapt to climate change with relative ease. The short generation time of these animals gives them a great advantage in adapting to environmental change. The opportunists whose reproduction depends only upon foraging conditions and energy balance should have no trouble adapting to new environments. Similarly, the desert and dry grassland rodents that rely on a predictive cue or cues provided by rainfall or new vegetation will probably also adapt relatively rapidly. This is really just another form of opportunism. Rodents whose reproduction is controlled by photoperiod will adapt more slowly because of the need to evolve new critical day lengths but, alternatively, this mode of control could be abandoned entirely or ignored in favour of foraging conditions as is seen today in the California vole and the desert rodents studied in Israel and Egypt.

If selection favours altering control by photoperiod in small rodents, how rapidly could this happen? The only concrete data addressing that question come from attempts to use selection in the laboratory to assess the potential rate at which reproductive photoperiodism might be lost in species that exhibit individual variation in photoresponsiveness (which, as argued earlier, is probably most of them living above $40^{\circ}$ latitude). A single generation of disruptive selection for and against reproductive photoresponsiveness in white-footed mice resulted in 80 per cent of the animals being responsive to photoperiod in the responsive line versus only 20 per cent responsive in the non-responsive line; these figures did not change appreciably over the next seven generations, however (Heideman \& Bronson 1991; P. D. Heideman 2008, personal communication). Likewise, several generations of selection for non-responsiveness in Siberian hamsters (Phodopus sungorus) also failed to fix this trait at 100 per cent (Goldman et al. 2000). Apparently, the degree of photoresponsiveness in a population of small rodents can change drastically in only a single generation but the trait cannot be lost entirely very quickly (see also Spears \& Clark 1988). However, as noted earlier, photoperiodic control in these animals can be ignored, switching instead to a reliance on foraging conditions without selection eliminating photoresponsiveness.

This discussion must end by noting again the profound gap in our knowledge that limits our ability to predict the future, namely what happens in the world's tropical habitats? Most researchers interested in seasonal reproduction live in the Temperate Zone and most study mammals adapted to the environmental conditions of these latitudes with a heavy 
emphasis on the role played by photoperiod. In contrast, most mammals live in the tropics where cues other than photoperiod come into play. We have hardly scratched the surface in learning about how the diverse environments regulate the mammals living here and the environmental conditions of the tropics today are the conditions of the higher latitudes of the future.

\section{REFERENCES}

Arroyo, L. J., Gallegos-Sanchez, J., Villa-Godoy, A., Berrueco, J. M., Perera, G. \& Valencia, J. 2007 Reproductive activity of Pelibuey and Suffolk ewes at $19^{\circ}$ north latitude. Anim. Reprod. Sci. 102, 24-30. (doi:10.1016/ j.anireprosci.2006.09.025)

Avigdor, M., Sulliavan, S. D. \& Heideman, P. D. 2004 Response to selection for photoperiod responsiveness on the density and location of mature GnRH-releasing neurons. Am. F. Physiol. Regul. Integr. Comp. Physiol. 288, R1226-R1236.

Bradshaw, W. E. \& Holzapfel, C. M. 2006 Evolutionary response to rapid climate change. Science 312, 1477-1478. (doi:10.1126/science.1127000)

Bradshaw, W. E. \& Holzapfel, C. M. 2007 Evolution of animal photoperiodism. Annu. Rev. Ecol. Evol. Syst. 38, 1-25. (doi:10.1146/annurev.ecolsys.37.091305.110115)

Bronson, F. H. 1989 Mammalian reproductive biology, pp. 51-52. Chicago, IL: The University of Chicago Press.

Bronson, F. H. 1995 Seasonal variation in human reproduction: environmental factors. Quart. Rev. Biol. 70, $141-164$.

Bronson, F. H. 1998 Global zones and reproduction. In Encyclopedia of reproduction, vol. 2 (eds E. Knobil \& J. D. Neill), pp. 452-460. San Diego, CA: Academic Press.

Bronson, F. H. 2004 Are humans seasonally photoperiodic? 7. Biol. Rhythms 19, 180-192. (doi:10.1177/ 0748730404264658)

Bronson, F. H. \& Heideman, P. D. 1992 Lack of reproductive photoresponsiveness and correlative failure to respond to melatonin in a tropical rodent, the cane mouse. Biol. Reprod. 46, 246-250. (doi:10.1095/biolreprod46.2.246)

Bronson, F. H. \& Heideman, P. D. 1994 Seasonal regulation of reproduction in mammals. In The physiology of reproduction (eds E. Knobil \& J. D. Neill), 2nd edn. New York, NY: Raven Press.

Castellano, J. M. et al. 2005 Changes in hypothalamic KISS-1 system and restoration of pubertal activation of the reproductive axis by kisspeptin in undernutrition. Endocrinology 146, 3917-3925. (doi:10.1210/en.2005-0337)

Crowley, T. J. 1994 Pangean climates. In Pangea: paleoclimate, tectonics and sedimentation during the accretion, zenith and breakup of a supercontinent, vol. 288 (ed. G. D. Klein), pp. 25-55. Special Papers. Geological Society of America.

Demas, G. E. \& Nelson, R. J. 1998 Social, but not photoperiodic, influences on reproductive function in male Peromyscus aztecus. Biol. Reprod. 58, 385-389. (doi:10. 1095/biolreprod58.2.385)

Desjardins, C., Bronson, F. H. \& Blank, J. L. 1986 Genetic selection for reproductive photoresponsiveness in deer mice. Nature 32, 172-173. (doi:10.1038/322172aO)

El-Bakry, H. A., Zahran, W. M. \& Bartness, W. M. 1998 Photoperiodic responses of four wild-trapped desert rodent species. Am. F. Physiol. Regul. Integr. Comp. Physiol. 275, R2012-R2022.

El-Bakry, H. A., Zahran, W. M. \& Bartness, R. J. 1999 Control of reproductive and energetic status by environmental cues in a desert rodent, Shaw's Jird. Physiol. Behav. 66, 657-666. (doi:10.1016/S0031-9384(98)00344-8)

Ellison, P. T. 2001 On fertile ground. Cambridge, MA: Harvard University Press.

Gockel, J. \& Ruf, T. 2001 Alternative seasonal reproductive strategies in wild rodent populations. F. Mammal. 82, 1034-1036. (doi:10.1644/1545-1542(2001)082< 1034:ASRSIW > 2.0.CO;2)

Goldman, S. L., Dhandapani, K. \& Goldman, B. D. 2000 Genetic and environmental influences on short-day responsiveness in Siberian hamsters. F. Biol. Rhythms 15, 417-428. (doi:10.1177/074873000129001503)

Goldman, B., Gwinner, E., Karsch, F. J., Saunders, D., Zucker, I. \& Ball, G. F. 2004 Circannual rhythms and photoperiodism. In Chronobiology: biological time keeping (eds J. D. Dunlap, J. J. Loros \& P. J. DeCoursey), pp. 107-144. Sunderland, MA: Sinaur Associates, Inc.

Goss, R. J. 1983 Deer antlers: regeneration, function and evolution. New York, NY: Academic Press.

Gower, B. A., Nagy, T. R. \& Stetson, M. H. 1997 Alteration of testicular response to long photoperiod by transient exposure to short photoperiod in collard lemmings (Dicrotonyx groenlandicus). F. Reprod. Fertil. 109, 257-262.

Heideman, P. D. 2000 Environmental regulation of reproduction. In The reproductive biology of bats (eds E. G. Chrichton \& P. Kutsch), pp. 469-499. New York, NY: Academic Press.

Heideman, P. D. \& Bronson, F. H. 1991 Characteristics of a genetic polymorphism for reproductive photoresponsiveness in the white-footed mouse (Peromyscus leucopus). Biol. Reprod. 44, 1189-1196. (doi:10.1095/biolreprod44. 6.1189)

Heideman, P. D. \& Bronson, F. H. 1992 A pseudoseasonal reproductive strategy in a tropical rodent, Peromyscus nudipes: correlates and causes. F. Reprod. Fertil. 95, 57-67.

Heideman, P. D. \& Bronson, F. H. 1993 Sensitivity of Syrian hamsters (Mesocricetus auratus) to amplitudes and rates of photoperiodic change typical of the tropics. F. Biol. Rhythms 8， 325-337. (doi:10.1177/0748730493008 00405)

Heideman, P. D., Bruno, T. A., Singly, J. W. \& Smedley, J. V. 1999 Genetic variation in photoperiodism in Peromyscus leucopus: geographic variation in an alternative life-history strategy. f. Mammal. 80, 1232-1242. (doi:10.2307/ 1383173)

Herbert, J. 1989 Neural systems underlying photoperiodic time measurement: a blueprint. Experientia 45, 965-972. (doi:10.1007/BF01953054)

Inouye, D. S., Barr, B., Armitage, K. B. \& Inouye, B. D. 2000 Climate change is affecting altitudinal migrants and hibernating species. Proc. Natl. Acad. Sci. 97, 1630-1633. (doi:10.1073/pnas.97.4.1630)

Jackson, C. \& Bernard, R. T. F. 1999 Short day length alone does not inhibit spermatogenesis in the seasonally breeding four-striped field mouse (Rhabdomys pumilio). Biol. Reprod. 60, 1320-1323. (doi:10.1095/biolreprod60.6.1320)

Jansen, H. T. \& Jackson, G. L. 1993 Circannual rhythms in the ewe: patterns of ovarian cycles and prolactin secretion under two different constant photoperiods. Biol. Reprod. 49, 627-634. (doi:10.1095/biolreprod49. 3.627)

Kaikusalo, A. \& Tast, J. 1984 Winter breeding of Microtine rodents at Kilpisjarvi, Finish Lapland. Spec. Publ. Carnegie Museum Nat. History 10, 243-252.

Kauppila, A., Kivela, A., Pakarinen, A. \& Vakkuri, O. 1987 Inverse seasonal relationship between melatonin and 
ovarian activity in humans in a region with a strong contrast in luminosity. F. Clin. Endocrinol. Metab. 65, $823-828$.

Kerbeshian, M. C., Bronson, F. H. \& Bellis, E. D. 1994 Variation in reproductive photoresponsiveness in a wild population of meadow voles. Biol. Reprod. 50, 745-750. (doi:10.1095/biolreprod50.4.745)

Krebs, C. J. 1993 Are lemmings large Microtus or small reindeer? A review of lemming cycles after 25 years and recommendations for future work. In The biology of lemmings (eds N. C. Stenseth \& R. A. Ims), pp. 247-260. London, UK: Academic Press.

Laundre, J. W. \& Hernandez, L. 2003 Total energy budget and prey requirements of free-ranging coyotes in the Great Basin desert of the western United States. F. Arid Environ. 55, 675-689. (doi:10.1016/S01401963(02)00316-6)

Lincoln, G. A. 1998 Photoperiod-melatonin relay in deer. Acta Vet. Hung. 46, 341-356.

Lynch, G. R., Heath, H. W. \& Johnston, C. M. 1981 Effect of geographical origin on the photoperiodic control of reproduction in the white-footed mouse, Peromyscus leuopus. Biol. Reprod. 25, 475-480. (doi:10.1095/biolre prod25.3.475)

Lynch, G. E., Sullivan, J. K., Heah, H. W. \& Tamarkin, L. 1982 Daily melatonin rhythms in photoperiod sensitivity and insensitive white-footed mice (Peromyscus leucopus). In The pineal and its hormones (ed. R. Ryder). New York, NY: A R Liss.

MacGregor, D. J. \& Lincoln, G. A. 2008 A physiological model of a circannual oscillator. F. Biol. Rhythms 23, 252-264. (doi:10.1177/0748730408316796)

Malpaux, B., Tricoire, H., Maillet, F., Daveau, A., Migaud, M., Skinner, C. C., Petetier, J. \& Chemineau, P. 2002 Melatonin and seasonal reproduction: understanding the neuroendocrine mechanisms using the sheep as a model. Reprod. Suppl. 59, 167-179.

Manning, J. \& Bronson, F. H. 1990 The effects of low temperature and food intake on ovulation in domestic mice. Physiol. Zool. 63, 938-948.

Millar, J. S. 2001 On reproduction in lemmings. Ecoscience 8, $145-150$.

Negus, N. C. \& Berger, P. J. 1977 Experimental triggering of reproduction in a natural population of Microtus montanus. Science 196, 1230-1231. (doi:10.1126/science. 323977)

Nelson, R. J., Dark, J. \& Zucker, I. 1983 Influence of photoperiod, nutrition and water availability on reproduction of male California voles (Microtus californicus). F. Reprod. Fertil. 69, 473-477.

Ogutu, J. O., Piepho, H.-P., Dublin, H. T., Bhola, N. \& Reid, R. S. 2008 Rainfall influences on ungulate population abundance in the Mara-Serengeti ecosystem. F. Anim. Ecol. 77, 814-829. (doi:10.1111/j.1365-2656. 2008.01392.x)

Parmesan, C. 2007 Influences of species, latitudes and methodologies on estimates of phenological response to global warming. Glob. Chan. Biol. 13, 1860-1872. (doi:10.1111/j.1365-2486.2007.01404.x)

Paul, M. J., Zucker, I. \& Schwartz, W. J. 2008 Tracking the seasons: the internal calendars of vertebrates. Phil. Trans. R. Soc. B 363, 341-361. (doi:10.1098/rstb.2007.2143)

Pearson, O. P. 1944 Reproduction in the shrew (Blarina brevicada Say). Am. F. Anat. 84, 39-93.

Pendergast, B. J. 2005 Internalization of seasonal time. Horm. Behav. 48, 503-511.

Pendergast, B. J., Kriegsfeld, L. J. \& Nelson, R. J. 2001 Photoperiodic polyphenisms in rodents: neuroendocrine mechanisms, costs and functions. Q. Rev. Biol. 76, 293-321.
Post, E. \& Forchhammer, M. C. 2008 Climate change reduces reproductive success of an Arctic herbivore through tropic mismatch. Phil. Trans. R. Soc. B 363, 2369-2375. (doi:10.1098/rstb.2007.2207)

Reichman, O. J. \& van de Graaff, K. M. 1975 Association between digestion of green vegetation and desert rodent reproduction. f. Mammal. 56, 503-506. (doi:10.2307/ 1379375)

Revel, F. G., Ansel, L., Klosen, P., Saboureau, M., Pevet, P., Mikkelsen, J. D. \& Simonneaux, V. 2007 Kisspeptin: a key link to seasonal breeding. Rev. Endocrinol. Metab. Disorders 8, 57-65. (doi:10.1007/s11154-0079031-7)

Roenneberg, T. \& Aschoff, J. 1990 Annual rhythm of human reproduction. I. Biology, sociology, or both. f. Biol. Rhythms 5, 195-216. (doi:10.1177/0748730 49000500303)

Rolf, H. J. \& Fischer, K. 1996 Serum testosterone, 5- $\alpha$ dihydrotestosterone and different sex characteristics in male fallow deer (Cervus dama): a long-term experiment with accelerated photoperiods. Comp. Biochem. Physiol. A Mol. Integr. Physiol. 115, 207-221. (doi:10.1016/ 0300-9629(96)00051-5)

Schneider, J. E. 2004 Energy balance and reproduction. Physiol. Behav. 81, 289-317. (doi:10.1016/j.physbeh. 2004.02.007)

Shanas, U. \& Haim, A. 2004 Diet salinity and vasopressin as reproduction modulators in the desertdwelling golden spiny mouse (Acomys russatus). Physiol. Behav. 81， 645-650. (doi:10.1016/j.physbeh.2004. 03.002)

Sicard, B., Maurel, J., Gautun, C. \& Boissin, J. 1988 Activation ou inhibition testiculaire par la photoperiode chez plusieurs especes de rongeurs saheliens: premiere mise en evidence d' une variation ciradacidenne de la photogonadosensibility. C. R. Acad. Sci. (Paris) 307, $11-17$.

Skogland, T. 1989 Comparative social organization of wild reindeer in relation to food, mates and predator avoidance. Adv. Ethol. 29, 1-74.

Spears, N. \& Clark, J. R. 1988 Selection in field voles (Microtus agrestis) for gonadal growth under short photoperiods. F. Anim. Ecol. 57, 61-70.

Stokkan, K.-A., van Oort, B. E. H., Tyler, N. J. C. \& Loudon, A. S. I. 2007 Adaptations for life in the Arctic: evidence that melatonin rhythms in reindeer are not driven by a circadian oscillator but remain acutely sensitive to environmental photoperiod. F. Pineal Res. 43, 289-293. (doi:10.1111/j.1600-079X.2007. 00476.x)

Takahashi, J. S., Hong, H., Ko, C. H. \& McDearmon, E. L. 2008 The genetics of mammalian circadian order and disorder: implications for physiology and disease. Nat. Rev. Genet. 9, 764-775. (doi:10.1038/nrg2430)

Van Vuren, D. \& Armitage, K. B. 1991 Duration of snow cover and its influence on life-history variation in ellow-bellied marmots. Can. F. Zool. 69, $1755-1758$.

Verme, L. M. \& Ozoga, J. J. 1987 Relationship of photoperiod to puberty in doe fawn whitetailed deer. F. Mammal. 68, 107-110. (doi:10.2307/ 1381052)

Wade, G. N. \& Jones, J. E. 2004 Neuroendocrinology of nutritional infertility. Amr. f. Physiol. Regul. Integr. Comp. Physiol. 287, R1277-R1296.

Wallis, J. 1995 Seasonal influence on reproduction in chimpanzees of Gombe National Park. Int. F. Primatol. 16, $435-451$.

West, C. C. 1985 Reproductive biology of Pteropus rodricensis. Myotis 23-24, 137-141. 
White, R. M. \& Bernard, R. T. F. 1999 Lack of response of the sub-tropical rodent (Saccostomus campestris) to a secondary plant compound, 6-methoxybenzoxazlinoneconsequences for reproductive strategy. S. Afr. F. Zool. 14, 108-113.

Woodfill, C. J., Wayne, I. M., Moenter, S. M. \& Karsch, F. I. 1994 Photoperiodic synchronization of a circannual reproductive rhythm in the sheep: identification of season specific cues. Biol. Reprod. 50, 965-967. (doi:10. 1095/biolreprod50.4.965)

Wube, T., Haim, A. \& Fares, F. 2008 Reproductive response of xeric and mesic populations of the spiny mouse Acomys to photoperiod acclimation. F. Arid Environ. 72, 440-447. (doi:10.1016/j.jaridenv.2007.06.014)

Zhang, C., Bosch, M. A., Levine, J. E., Ronnckleiv, O. K. \& Kelly, M. J. 2007 Gonadotropin-releasing hormone neurons express $\mathrm{K}_{\mathrm{ATP}}$ channels that are regulated by estrogen and responsive to glucose and metabolic inhibition. F. Neurosci. 27, 10 153-10 164. (doi:10.1523/JNEUR OSCI.1657-07.2007)

Zucker, I. 2001 Circannual rhythms. In Handbook of behavioural neurobiology, vol. 12 (eds S. Takalhashi, F. W. Turek \& R. Y. Moore), pp. 509-528. New York, NY: Kluwer Academic Publishers/Plenum Press. 